\title{
Mature cystic ovarian teratomas: Relationship between histopathological contents and clinical features
}

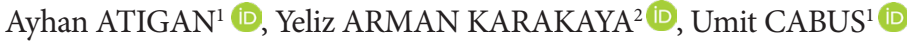 \\ ${ }^{1}$ Department of Obstetrics and Gynecology, School of Medicine, Pamukkale University, Denizli, Turkey. \\ ${ }^{2}$ Department of Pathology, School of Medicine, Pamukkale University, Denizli, Turkey. \\ Corresponding Author: Ayhan ATIGAN \\ E-mail: dratigan@hotmail.com \\ Submitted: 04.01.2021 Accepted: 12.04 .2021
}

\begin{abstract}
Objectives: Mature cystic teratomas (MCT) originate from three germ layers: ectoderm, mesoderm and endoderm. The predictive significance of tumor markers in mature cystic teratomas is still unclear. In this study, we aimed to evaluate the predictive value of tumor markers in ovarian MCTs and histopathological contents of tumor.

Materials and Methods: The data of 106 patients who were operated for ovarian MCT between 2015 and 2020 were retrospectively analysed. In addition, slides in the pathology archive were re-examined under a microscope to evaluate their histopathological contents.

Results: The average age of the patients was $35.7 ; 26.7$ in the cystectomy group and 42.1 in the oophorectomy group $(p=0.000)$. The ratio of tumor markers exceeding the cut off value for carbohydrate antigen (CA 19-9), lactate dehydrogenase (LDH), cancer antigen (CA 125), carcinoma antigen (CA 15-3), carcinoembryonic antigen (CEA) were $45.2 \% ; 47.7 \% ; 8.15 \% ; 12.3 \%$; $6.9 \%$, respectively. Histopathological examination of MCTs revealed 99.1\% ectoderm, $45.3 \%$ mesodermal, $39.6 \%$ endodermal origin.

Conclusion: Mature cystic teratoma is a benign tumor of the reproductive age that contains three germ layers in various proportions. LDH and CA 19-9 can be a helpful tool in predicting mature cystic teratomas.

Keywords: Mature cystic teratoma, Germ layers, Tumor markers
\end{abstract}

\section{INTRODUCTION}

Ovarian germ cell tumors (OGCT) are neoplasms in which malignant cells form in the germ cells of the ovary. OGCTs are subdivided into categories as teratomas (benign cystic mature teratomas, immature teratomas), dysgerminomas, yolk sac tumors, mixed germ cell tumors (yolk sac, dysgerminoma, and/or embryonal carcinoma) and rare ones (pure embryonal carcinomas, nongestational choriocarcinomas, and pure polyembryoma). Dysgerminoma, immature teratoma, yolk sac tumors, and mixed germ cell tumors account for 90 percent of malignant OGCTs cases [1]. OGCTs arise primarily in young women between 10 and 30 years of age and represent 70 percent of ovarian neoplasms in this age group [2].

A teratoma is a tumor made up of several different types of tissues, such as hair, muscle, teeth, or bone. Teratoma is a word introduced by Virchow in 1863. The term comes from the Greek words for "monster" and "tumor" [3]. Ovarian teratomas include mature cystic teratomas (MCTs), immature teratomas, and monodermal teratomas (e.g., struma ovarii, carcinoid tumors, and neural tumors) [4].

Mature cystic teratoma originates from primordial germ cells and histologically includes at least two of the three germ layers ( ectoderm, endoderm and mesoderm) [5,6]. It is the most common tumor (60\%) among benign tumors [5]. Since, MCTs tend to arise at an early age, it is undoubtedly also encountered during pregnancy [7]. Dermoid cyst means a MCT comprising specially hair and other structures characteristic of normal skin and other tissues derived from the ectoderm [8]. One of the most common locations is the ovary. MCT is liable for $20 \%$ of all ovarian neoplasms [7,9]. Although, dermoid cysts are commonly unilateral, $10-12 \%$ are bilateral. While all ovarian

How to cite this article: Atigan A, Arman Karakaya Y, Cabus U. Mature cystic ovarian teratomas: Relationship between histopathological contents and clinical features. Marmara Med J 2021; 34(2):167-174. doi: 10.5472/marumj.925209 
cysts can range in size from very small to quite large, dermoid cysts are not classified as functional cysts.

Alternative treatments should be considered before making the surgery decision. In many cases, the expectant approach may be appropriate for patients, as it will take years before the cyst can reach large sizes. Complications exist, such as torsion, rupture, and infection, although their incidence is rare. Dermoid ovarian cysts which are larger present complications which might require removal by either laparoscopy or laparotomy [10].

It is impossible not to benefit from radiological imaging while establishing the initial diagnosis. Magnetic resonance imaging (MRI), computed tomography (CT) and ultrasonography (USG) are used to define the location and prominent features of MCT. It is easy to apply the USG as first step in clinic. However, MRI and CT are more useful in identifying MCT. Whereby the recording of images such as MRI or CT, it is easier to compare the natures of the cyst with past examinations in patients with an expectant approach.

Several serum tumor markers may increase in MCTs. These specific serum tumor markers are cancer antigen 125 (CA125), carcinoma antigen 15-3 (CA 15-3), carbohydrate antigen 19-9 (CA 19-9), carcinoembryonic antigen (CEA), and lactate dehydrogenase (LDH) [11-15]. However, these are not specific tumor markers. In addition, there is no study stating to what extent these markers are affected by MCT content. We present to reveal the relationship between histopathological contents and serum tumor markers of MCTs. In this study we also aimed to investigate to surgical information and clinical findings.

\section{MATERIALS and METHODS}

Ovarian tumors reported as mature cystic teratoma between January 2015 - January 2020 at Pamukkale University Pathology Department, were included in this retrospective study. Before conducting the study, approval was obtained from the Pamukkale University, Shool of Medicine Clinical Research Ethics Committee (19.11.2019-20). Patient information was accessed from the hospital record-archive system. 106 mature cystic teratoma patients were included in the study. While investigating patients with ovarian teratoma, 3 patients with immature teratoma were detected. Immature teratoma patients were not included in the analysis. Patients were imaged with at least one of MRI, CT and USG before their diagnosis was confirmed by pathology. Characteristic features, diameter and laterality of the tumors were noted. Age, pregnancy, menopause status, ovarian torsion, intraabdominal fluid and frozen section evaluation status, incision, surgical method, pathological findings and laboratory values were analyzed. Each patient's medical records were reviewed retrospectively. Preoperative serum analysis were evaluated for tumor markers when available, CA-125 ( $\mathrm{n}=76)$; CA 15-3 ( $\mathrm{n}=73$ ); CA 19-9 $(\mathrm{n}=73)$; CEA $(\mathrm{n}=72)$ and $\mathrm{LDH}(\mathrm{n}=44)$. Cut off values of these tumor markers were $35 \mathrm{U} / \mathrm{mL} ; 25 \mathrm{U} / \mathrm{mL} ; 27 \mathrm{U} / \mathrm{mL} ; 4.7 \mathrm{ng} /$ $\mathrm{mL}$ and $214 \mathrm{U} / \mathrm{L}$, respectively. Hematoxylin-eosin (H-E) stained slides of teratoma tissues were re-examined, thus, endodermal, mesodermal or ectodermal origin of tissues were analyzed. The slides examined were evaluated by at least two researchers, one being a pathologist, with a Nikon eclipse e200 microscope.

\section{Statistical Analysis}

The IBM SPSS Statistics (Version 21.0, SPSS Inc.) program was used for the statistical analyses. When the study data were evaluated, the relationships between descriptive statistical methods for mean \pm standard deviation (SD), median, minumum (Min) - maximum (Max) were used. Categorical variables were calculated as rate (\%) and the Chi-square test was performed. Due to the failure of the normality test (Kolmogorov Smirnov), comparisons between groups were made using the Mann Whitney $U$ non-parametric test. p-value $<0.05$ was considered statistically significant.

\section{RESULTS}

A total of 106 cases of MCT were studied. Table I presents demographic, clinical and surgical data of the patients. The mean age of the cases was 35.7 and the median age was 32.5 (9-84) years. Nine of all patients were pregnant, 24 were postmenopausal and 11 were children. Five of the pregnant women were in term and four was in the second trimester (Figure 1A). While only one patient had ruptured cyst, five patients had torsion. Approximately half of the MCTs were located on the right side, while nine of MCTs were bilateral. The mean diameter of the cysts was $6.7 \mathrm{~cm}$ with preoperative radiological imaging. The average tumor volume obtained by examining the pathology reports was $206 \mathrm{~cm}^{3}$. During surgery, abdominal fluid sample was obtained from 36 cases for cytological examination, and 41 cases were evaluated with a rapid pathological examination, frozen section. The initial diagnoses revealed by imaging, anamnesis and physical examination were as follows; adnexal mass $17 \%$, Cesarean section $(\mathrm{C} / \mathrm{S}) 4.7 \%$, endometrioma $0.9 \%$, dysgerminoma $0.9 \%$, mature cystic teratoma (MCT - dermoid cyst) (Figure 1B) $74.5 \%$, acute abdomen $1.9 \%$. In one patient with acute abdomen, appendicitis (Figure 1C) was present concurrently with MCT. Laparotomy was the preferred approach for the $80.2 \%$ cases while laparoscopy was performed for $18.9 \%$ of the cases. There was only one vaginal operation. The most preferred method in laparotomy cases was pfannestiel incision.

Due to the retrospective nature of our study, preoperative tumor marker values could not be achieved in all patients (Table II). Average values for CA 19-9 $(\mathrm{n}=73)$, LDH $(\mathrm{n}=44)$, CA 125 ( $\mathrm{n}=$ 76), CA 15-3 ( $n=73)$, CEA $(n=72)$ were $43.9,216.1,22.2,16.6,2.1$, respectively. The percentage of those who exceeded the cut off value in the same order were $45.2 \%, 47.7 \%, 15.8 \%, 12.3 \%, 6.9 \%$. CA $19-9$ was statistically significantly higher in 33 patients who exceeded the cut off value than lower mean group $(83.1 \mathrm{U} / \mathrm{mL}$ vs $11.5 \mathrm{U} / \mathrm{mL})$ $(\mathrm{p}=0.03)$. CA 19-9 was statistically lower in tumors containing all three germ layers than others $(23.9 \mathrm{U} / \mathrm{mL}$ vs $51.9 \mathrm{U} / \mathrm{mL})(\mathrm{p}=0.007)$. High CA 19-9 values had no effect on other parameters.

The macroscopic view of a tumour is presented in figure $2 \mathrm{~A}$. Microscopic examination of the most of the mature teratomas revealed squamous epithelium, adnexal structures and adipose tissue. A total of 42 cases (39.6\%) out of 106 cases showed 
endoderm (Figure 2), 48 cases (45.3\%) mesoderm (Figure 3) and 105 cases (99.1\%) ectoderm (Figure 4) derived components (Table III). There were 29 (27.3\%) cases including all three germ layers. Nine cases were bilateral. Ovarian squamous epithelium and skin adnexal structures was seen in total $94.3 \%$. There were serous epithelium, serous papillary cyst and mucinous epithelium in total 22, 5 and 19 of the cases, respectively. Adipose tissue was detected in 24, glial tissue in 22 and chondroid tissue in 36 cases. In addition, psammoma body, choroid plexus, bronchial epithelium, thyroid tissues, teeth, salivary gland, bones, bone marrow, melanin pigment, ganglion, peripheral nerve tissue, lymph node were observed. Statistically significant mesodermal component predominance was observed in younger ages (32.3 \pm 17.28 vs $38.5 \pm 15.9)(\mathrm{p}=0.025)$.

Comparisons in accordance with the surgical method options showed the comparable distribution of patient age, tumor diameter and volume among groups by Mann-Whitney U-test (Table IV). The mean age of 44 patients who underwent cystectomy was 26.7, while the mean age of 62 patients who underwent oophorectomy was $42.1(\mathrm{p}=0.000)$. The preoperative diameters of teratomas were smaller in the cystectomy group than those in the oophorectomy group $(5.8 \mathrm{~cm}$ vs $7.3 \mathrm{~cm}$, $\mathrm{p}=0.023)$. When the volumes calculated in histopathological examinations were compared, the cystectomy group had smaller sizes $\left(80.1 \mathrm{~cm}^{3}\right.$ vs $\left.296.4 \mathrm{~cm}^{3}, \mathrm{p}=0.000\right)$. The majority of those examined in the frozen section consisted of those undergoing oophorectomy. Tumors examined in frozen section were found to have a larger diameter (mean 7.8 vs $6.1 \mathrm{~cm}, \mathrm{p}=0.01$ )
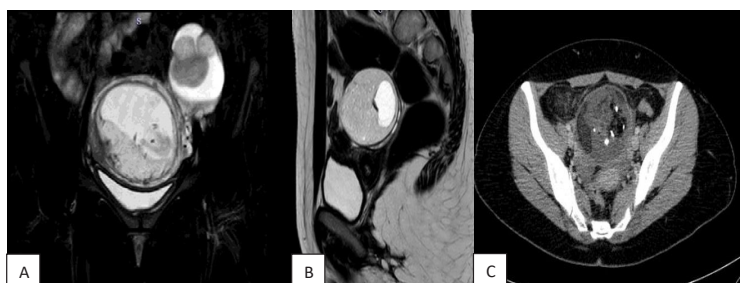

Figure 1. (A)View of pregnant uterus in the pelvis and a mass with cysticsolid content in the left ovary on MRI. (B) Sagittal view on MRI of the MCT case, which has a cystic structure in its centre with adipose component about $5 \mathrm{~cm}$ in diameter, which pushes the ovarian parenchyma into the periphery. (C) Axial view of the pelvis by CT imaging shows a large cystic mass containing fat and calcification in the case of perforated appendicitis.

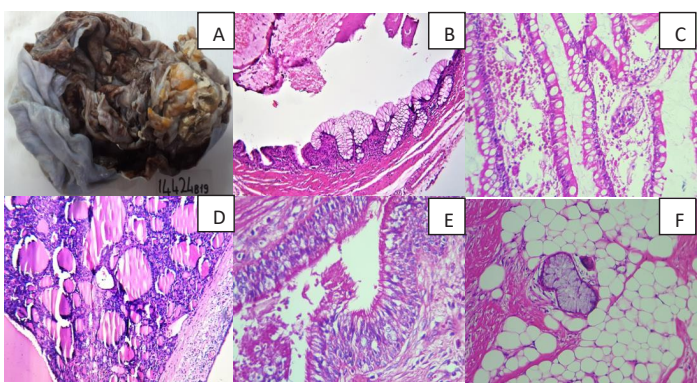

Figure 2. Endodermal components and macroscopic view of MCT. (A) Multi-cystic structure, thickening on the wall, adipose tissue and sebaceous contents are observed in several areas. (B) Cystic area covered with mucinous epithelium, $H-E, x 100$. (C) Intestinal metaplasia area, $H-E, x 200$. (D) Thyroid follicle structures containing colloid, $H-E, x 200$. (E) Ciliated pseudo-sturative respiratory epithelium, H-E, X400. (F) Mucinous gland in adipose tissue, $H-E, x 400$.

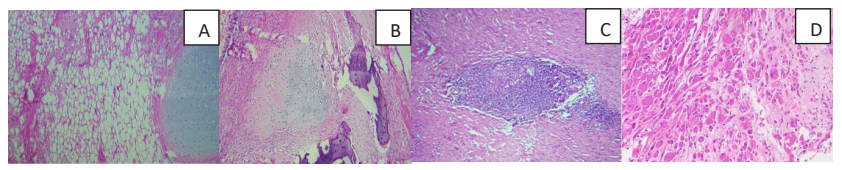

Figure 3. Mesoderm components. (A) Areas containing adipose and chondroid tissue, H-E, x100. (B) Chondroid tissue and osseous metaplasia, $H-E, X$ 40. (C) Lymphoid follicle, H-E, X100. (D) Degenerate myocytes, $H-E, x 200$.

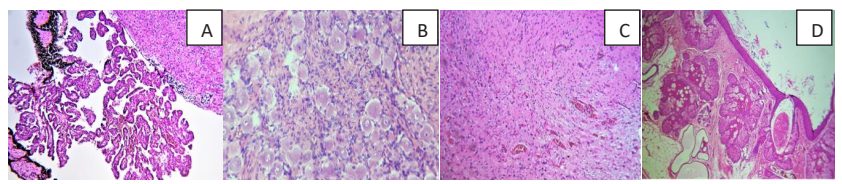

Figure 4. Ectodermal components. (A) Choroid plexus papilloma and melanin pigmented areas, $H-E$, x100. (B) Ganglion cells, $H-E$, x400. (C) Glial tissue, $H-E, x 100$. (D) Skin and skin adnexal, $H-E, x 40$ 
Table I. Demographic, clinical and surgical data

$\begin{array}{lc}\text { Age (years, mean } \pm \text { SD) } & 35.7 \pm 16.7 \\ \text { Min-Max } & 9-84 \\ \text { Pregnancy (\%) } & 9(8.5 \%) \\ & \\ \text { Post-menopause } & 24(22.6 \%)\end{array}$

Children $\quad 11(10.3 \%)$

$\begin{array}{lc}\text { Lateralization } & \\ \text { Unilateral left } & 43(40.6 \%) \\ \text { Unilateral right } & 54(50.9 \%) \\ \text { Bilateral } & 9(8.5 \%) \\ \text { Radiologic diameter }(\mathrm{cm}, \text { mean } \pm \text { SD) } & 6.76 \pm 3.39 \\ \quad \text { Min-Max } & 1.5-24 \\ \text { Histopathological tumor volume }(\mathrm{cm} 3, \text { mean } \pm S D) & 206.9 \pm 530.9 \\ \quad \text { Min-Max } & 1.6-3494\end{array}$

Torsion

$5(4.7 \%)$

\begin{tabular}{lc} 
Frozen section & $41(38.7 \%)$ \\
Intraabdominal fluid examination & $36(34.0 \%)$ \\
Initial diagnosis & \\
$\quad$ Adnexal mass & $18(17 \%)$ \\
Cesarean section (C/S) & $5(4.7 \%)$ \\
Endometrioma & $1(0.9 \%)$ \\
$\quad$ Dysgerminoma & $1(0.9 \%)$ \\
Mature cystic teratoma (MCT- dermoid cyst) & $79(74.5 \%)$ \\
Acute abdomen & $2(1,9 \%)$ \\
Surgical method & $85(80.2 \%)$ \\
$\quad$ Laparotomy & $20(18.9 \%)$ \\
Laparoscopy & $1(0.9 \%)$ \\
Vaginal & \\
Type of incision in laparotomy & $69(81.2 \%)$ \\
Pfannenstiel & $12(14.1 \%)$ \\
Infraumbilical median incision (IMI) & $4(4.7 \%)$ \\
\hline IMI + Supraumblical median incision &
\end{tabular}

Table II. Preoperative serum levels of tumor markers

\begin{tabular}{|c|c|c|c|c|c|}
\hline $\begin{array}{l}\text { Tumor } \\
\text { markers }\end{array}$ & $\begin{array}{l}\text { Cut-off } \\
\text { value }\end{array}$ & Mean \pm SD & Median & $\begin{array}{l}\text { Min- } \\
\text { Max }\end{array}$ & $\begin{array}{l}\text { Cut-off } \\
\text { exceeding } \\
\text { rate }(\%)\end{array}$ \\
\hline $\begin{array}{c}\text { CA } 19-9 \\
\mathrm{~N}=73\end{array}$ & $27 \mathrm{U} / \mathrm{mL}$ & $43.9 \pm 67.9$ & 23.5 & $0.6-494.0$ & $\begin{array}{c}33 / 73 \\
(45.2 \%)\end{array}$ \\
\hline $\begin{array}{l}\text { LDH } \\
\mathrm{N}=44\end{array}$ & $214 \mathrm{U} / \mathrm{L}$ & $216.1 \pm 70.9$ & 206.5 & $\begin{array}{l}99.0- \\
408.0\end{array}$ & $\begin{array}{c}21 / 44 \\
(47.7 \%)\end{array}$ \\
\hline $\begin{array}{l}\text { CA } 125 \\
\mathrm{~N}=76\end{array}$ & $35 \mathrm{U} / \mathrm{mL}$ & $22.2 \pm 18.5$ & 15.7 & $5.3-132.0$ & $\begin{array}{c}12 / 76 \\
(15.8 \%)\end{array}$ \\
\hline $\begin{array}{c}\text { CA } 15-3 \\
N=73\end{array}$ & $25 \mathrm{U} / \mathrm{mL}$ & $16.6 \pm 7.2$ & 16.5 & $3.7-34.1$ & $9 / 73(12.3 \%)$ \\
\hline $\begin{array}{l}\text { CEA } \\
\mathrm{N}=72\end{array}$ & $\begin{array}{c}4.7 \mathrm{ng} / \\
\mathrm{mL}\end{array}$ & $2.1 \pm 1.6$ & 1.7 & $0.2-9.2$ & $5 / 72(6.9 \%)$ \\
\hline
\end{tabular}

Table III. Classification according to the germ layers and the components content $(N=106)$

\begin{tabular}{|c|c|c|}
\hline \multicolumn{3}{|c|}{ Contains all three germ lavers } \\
\hline \multicolumn{3}{|c|}{$n=29$ percentage $27.3 \%$} \\
\hline $\begin{array}{c}\text { Component/Quantity } \\
(\%)\end{array}$ & Component/Quantity (\%) & $\begin{array}{c}\text { Component/Quantity } \\
(\%)\end{array}$ \\
\hline Ectoderm & Mesoderm & Endoderm \\
\hline $105(99.1 \%)$ & $48(45.3 \%)$ & $42(39.6 \%)$ \\
\hline Skin & Chondroid tissue & Mucinous epithelium \\
\hline $104(98.1 \%)$ & $36(34.0 \%)$ & $19(17.9 \%)$ \\
\hline Skin attachment & Adipose tissue & Thyroid tissue \\
\hline $100(94.3 \%)$ & $24(22.6 \%)$ & $8(7.5 \%)$ \\
\hline Glial tissue & Serous epithelium & Intestinal epithelium \\
\hline $22(20.8 \%)$ & $22(20.8 \%)$ & $4(3.8 \%)$ \\
\hline Choroid plexus & Osteoid tissue & Lymphatic gland \\
\hline $4(3.8 \%)$ & $7(6.6 \%)$ & $1(0.9 \%)$ \\
\hline Ganglion & Dental tissue & Salivary gland \\
\hline $4(3.8 \%)$ & $6(5.7 \%)$ & $1(0.9 \%)$ \\
\hline Sebaceous gland & Serous papillary cyst & Bronchial epithelium \\
\hline $2(1.9 \%)$ & $5(4.7 \%)$ & $1(0.9 \%)$ \\
\hline Peripheral nerve & Muscle tissue & \\
\hline $1(0.9 \%)$ & $5(4.7 \%)$ & \\
\hline Melanin pigment & Bone marrow & \\
\hline $1(0.9 \%)$ & $1(0.9 \%)$ & \\
\hline Psammoma body & & \\
\hline $1(0.9 \%)$ & & \\
\hline
\end{tabular}


Table IV. Comparison of patients undergoing cystectomy and oophorectomy

\begin{tabular}{|c|c|c|c|}
\hline Parameters & $\begin{array}{l}\text { Cystectomy } \\
(\mathrm{N}=44)\end{array}$ & $\begin{array}{l}\text { Oophorectomy } \\
(\mathrm{N}=62)\end{array}$ & p value ${ }^{b}$ \\
\hline Age (years, mean \pm SD) & $26.7 \pm 7.1$ & $42.1 \pm 18.6$ & 0.000 \\
\hline $\begin{array}{l}\text { Radiologic diameter }(\mathrm{cm} \text {, mean } \\
\pm \mathrm{SD})\end{array}$ & $5.8 \pm 2.5$ & $7.3 \pm 3.7$ & 0.023 \\
\hline $\begin{array}{l}\text { Histopathological tumor } \\
\text { volume }(\mathrm{cm} 3 \text {, mean } \pm \mathrm{SD})\end{array}$ & $80.1 \pm 136.8$ & $296.4 \pm 672.4$ & 0.016 \\
\hline Frozen section $(\mathrm{N})^{\mathrm{a}}$ & $7 / 44$ & $34 / 62$ & 0.02 \\
\hline
\end{tabular}

${ }^{a} p=0.02$ by Chi-square test, ${ }^{b} p$ value $<0.05$ was considered statistically significant

\section{DISCUSSION}

Mature cystic teratomas are benign tumors of the reproductive age that contains three germ layers in various proportions. Our findings show that simultaneous elevation of CA 19-9 and LDH may be a helpful tool in predicting MCTs.

Mature cystic teratomas, commonly referred to as dermoid cysts, which corresponds to $95 \%$ of ovarian teratomas, is one the leading causes of benign tumors in premenopausal women [16]. While these cysts are seen in adults at the rate of $20 \%$, they make up half of the pediatric ovarian tumors [2,7]. Accordingly, the average age was found to be $35.7 \pm 16.7$ in the current study. Sushma et al. reported that third and fourth decade patients accounted for two thirds of all patients [17]. In this current study, less than half of all MCTs were seen in this age group. Comerci et al. (517 cases), Ayhan et al. (501 cases) and Kikkawa et al. (92 cases) reported a mean tumor diameter of the cyst as $6.4,7.0$ and $8.8 \mathrm{~cm}$, respectively $[6,16,18]$. We found that the radiological diameter was similar to the literature with 6.76 $\pm 3.39 \mathrm{~cm}$. In accordance with the study of Sushma et al., the unilaterality with dominance of right ovary with $50.9 \%$ was detected in our study [17]. Bilaterality was observed in $8.5 \%$ of our cases while in previous studies, approximately $10-14 \%$ of cases were bilateral $[16,18-19]$. The mean volume calculated in histopathological examinations was $206.90 \pm 530.90 \mathrm{~cm}^{3}$ in the present study. In the study of Eskicioglu et al., while the average tumor volume is $128.2 \mathrm{~cm} 3$, we obtained that the high rate in our study using the same calculation formula (volume calculation of the ellipsoid shape ovary= longitudinal ${ }^{\star}$ transverse ${ }^{\star}$ anteroposterior diameter ${ }^{\star} 0.52$ ) [20]. Five cases in our data had torsion in conformity with the study of Ayhan et al. [16]. In our study three of the five patients with torsion underwent oophorectomy and two had cystectomy. Initial diagnosis was in compliance with pathologic diagnosis in three quarters of the patients.

Mature cystic teratoma is both the most common germ cell neoplasm and the most common removable ovarian neoplasm [21]. More than $90 \%$ of germ cell neoplasm evolve in gonads (ovaries and testicles). Partlow and Taybi also suggested that the most common teratoma site was ovary [22]. The remaining extragonadal part can appear in other parts of the body such as mediastenium, central nervous system, retroperitoneum and sacracoccygeal teratoma [23]. Most MCTs are nonviolent, such that abdominal pain or other nonspecific symptoms come out in a little group with MCT. Thus, the tumor is commonly noticeable in routine physical examination or radiological evaluation for different reasons and detected incidentally during abdominal surgery [24]. Some authors suggest non-surgical treatment of small $(<6 \mathrm{~cm})$ tumors due to the fact that MCTs expand into an average rate of $1.8 \mathrm{~mm}$ per year. This expectant therapy is currently a topic in debate [25]. Our study shows that the tumor sizes of the operated patients are distributed between 1.5 to 24 $\mathrm{cm}$.

Mature cystic teratoma has own characteristic cystic structure. Since, the cyst may originate from any three germ layers, it contains many tissues. The characteristic morphological appearance of MCTs are the multi-cystic strict mass (Rokitansky nodule) with hair, teeth, and sebaceous material which is sticky and sniffy $[6,26]$. Teratomas dominated by ectodermal tissues are specially called dermoid cysts. In the study of Caruso et al., ectodermal, mesoderml and endodermal origin were found be $100 \%, 73 \%$ and $30 \%$ of the cases, respectively [27]. In our study, ectodermal, mesoderml and endodermal origin were $99.1 \%$, $45.3 \%$ and $39.6 \%$, respectively. In addition, mesodermal content was present more frequently at a younger age. Endoderm and ectoderm contents did not differ by age. The percentage of those containing all three germ layers was $27.3 \%$. Varma et al., studied on 72 teratomes, analyzed the cyst contents at the microscopic appearance and reported that respiratory epithelium in 3 cases, glial tissue in 2 cases, cerebellar tissue in 1 case, choroid plexus in 1 case, teeth in 5 cases, bone and cartilage tissue in 13 cases [28]. In our study, similar to this study, there were 6 teeth and 1 bronchial epithelium. However, unlike this study, we detected 36 cartilage tissues, 22 glial tissues, 4 choroid tissues. In the study of Shin et al., 13 cases were examined histopathologically, 8 of them had glial tissue and 3 of them had thyroid tissue [29]. The most common tissues found in our study are; skin $98.1 \%$ and skin adnexal structures $94.3 \%$ followed by chondroid tissue $34.0 \%$, adipose tissue $22.6 \%$, serous epithelium $20.8 \%$, glial tissue $20.8 \%$, mucinous epithelium $17.9 \%$.

Ustunyurt et al. reported elevated percentage for CA 19-9 (39.6\%) and CA 125 (23.3\%) [11]. According to our data obtained from 73 patients, CA 19-9 was statistically significantly higher in 33 patients who exceeded the cut off value. Ito reported that the mean value for CA $19-9$ was $32.9 \mathrm{U} / \mathrm{ml}$ in the belove cut-off group and $83.8 \mathrm{U} / \mathrm{ml}$ in the above cut-off group [12]. In our study, it was $83.1 \mathrm{U} / \mathrm{mL}$ for the above cut-off group. However, the values for belove cut-off group of our study $(11.5 \mathrm{U} / \mathrm{mL})$ was lower than that study. We observed that CA 19-9 was statistically lower in tumors containing all three germ layers than others. In studies involving the larger patient groups, attention should be paid to how histopathological content affects tumor markers. Mikuni et al. reported the ratio of CA 19-9, CA 125, CEA and $\mathrm{LDH}$ who exceeded the threshold value, as $45.5 \%, 12.7 \%, 1.6 \%$, $0.6 \%$, respectively [13]. In our study, the percentage of those who were high compared to the cut off value for LDH, CA199, CA125, CA15-3, CEA was 47.2\%, 45.2\%, 15.8\%, 12.3\%, 6.9\% respectively. CA 19-9 and CA 15-3 were higher proportionally in our study compared to the published study of Var et al. [14]. LDH enzyme are very sensitive indicators of the cellular metabolic state, aerobic or anaerobic direction of glycolysis, 
activation status and malignant transformation. Few published reports investigated the relationship between $\mathrm{LDH}$ and MCTs. Therefore, the data about this subject are limited. Mikuni et al. reported LDH level was no significant in mature cystic teratomas [13]. Contrary, Konishi et al. declared that LDH is useful tumor marker for specific histological type of dysgerminoma and other ovarian solid germ cell tumors [15]. Our data support that LDH levels significantly high in MCTs. Further studies are needed to clarify this issue.

The frozen section is a pathological laboratory procedure to perform rapid microscopic analysis of a specimen. Although there are no frozen section studies of ovarian MCTs in the literature, it is a useful pathological examination method in masses suggesting malignancy [30]. In our study, the pathological material of $41(38.7 \%)$ patients was studied with frozen section. Malignancy was not observed in frozen section examination of MCTs. This high frozen rate of study obtained from our study shows that MCTs in benign nature are not morphologically innocent for the surgeon. In our study, cytological examination of intraabdominal fluid was performed in 36 (34.0\%) cases, althoug they were negative in terms of malignancy.

The malignant teratoma account for 3-4\% of ovarian carcinomas. The squamous epithelium covers the wall of the cyst and and hyalinized ovarian stroma often covers the outer surface [19]. MCT shows malignant transformation in $1-2 \%$ of the cases, squamous cell carcinoma being the commonest [31,32]. Teratomas commonly are classified using the Gonzalez-Crussi grading system: 0 or mature (benign); 1 or immature, probably benign; 2 or immature, possibly malignant (cancerous); and 3 or frankly malignant [8]. The ratio of immature teratomas to total ovarian teratomas is between $1-3 \%$ in the literature. In our study this ratio is $2.75 \%[16,33]$. All cases were benign in our study.

Which surgical method should we prefer in the treatment of mature cystic teratomas, laparotomic or laparoscopic? Actually factors influencing the choice of suitable management depend on patient's age, reproductive plans, pre-operative findings, the size of the mass and the surgeon's experience. The benefits of laparoscopic surgery are less postoperative pain with better wound healing, mini scarring, short hospital stay and early return to routine daily work compared to laparotomy [34]. Usually, laparotomy is preferred in large tumors, presence of previous surgical operations and pelvic adhesion. In our study, $18.9 \%$ of the cases were performed with laparoscopy, while $80.2 \%$ were with laparotomy. In addition, one (0.9\%) of the cases underwent vaginal hysterectomy and bilateral salpingooferectomy. The common incision type in laparotomy was pfannestiel incision. The tumor's diameter of the laparoscopy group in our study was significantly smaller than laparotomy $(5.4 \pm 1.4$ vs $7.1 \pm 3.6 .6)$ $\mathrm{cm}(\mathrm{p}=0.001)$. However, we observed no significant difference in age between laparoscopy $(31.5 \pm 18.6 .6)$ and laparotomy $(36.4$ \pm 16.1.1) group.

The tumor diameter $(\mathrm{cm})$ of the laparoscopy group in our study was significantly smaller than laparotomy $(5.4 \pm 1.4$ vs $7.1 \pm 3.6$ $\mathrm{cm})(\mathrm{p}=0.001)$. However, there was no difference between the laparoscopy $(n=20,31.5 \pm 18.6)$ and laparotomy $(n=85$, $36.4 \pm 16.1)$ as the surgical method according to age $(\mathrm{p}=0.232)$.
An oophorectomy should be performed for all peri - or postmenopausal patients, independently of the aspect of the cyst. In younger patients, ovarian cystectomy can be considered. There was a significant difference in the decision of cystectomy versus oophorectomy in terms of age $(26.7 \pm 7.1$ vs $42.1 \pm 18.6$, $\mathrm{p}<0.001)$, radiological diameter $(\mathrm{cm})(5.88 \pm 2.5$ vs $7.38 \pm 3.7$, $\mathrm{p}=0.023)$, tumor volume $\left(\mathrm{cm}^{3}\right)(80.1 \pm 136.8$ vs $296.4 \pm 672.4$, $\mathrm{p}=0.016)$. As these data were small in the cystectomy group, frozen section examination rate was also lower (17.1\% vs $83.9 \%$, $\mathrm{p}=0.02$ ). Ayhan et al. reported the cyst diameter ( 7.0 vs 7.0 ) were similar in both groups, as the mean age of the cystectomy group lower than the oophorectomy group (27.9 vs 31.2$)$ [16]. In the study of Uysal et al., cystectomy cases had a mean diameter of $6.7 \mathrm{~cm}$ while the mean diameter for ooferectomy cases was $9.1 \mathrm{~cm}$ [35]. Although laparoscopic surgery has been more preferred in recent years, laparotomy should be unconsidered as a defeat, but as a safe alternative for prominent cases. The surgeon must keep in mind the risk of a laparoscopic rupture and spillage of a malignant tumour, and must weigh the risks of laparoscopy versus laparotomy. There was only one ruptured MCT case where we could access information from patient files. Laparotomy was performed in $90.1 \%$ of the cases in a study of Sahraoui et al [33].

Mature cystic teratoma is one of the most common benign ovarian neoplasms encountered during pregnancy (24-40\%) [6]. Sahraoui et al. reported $19.8 \%$ of MCTs as pregnant [33]. In this article, the pregnancy rate was found to be less than previous studies. The pregnancy rate is $8.5 \%$. While five of the pregnant cases were performed simultaneous cesarean section, the other four cases (15-18 weeks) were still in the second trimester.

Based on the literature and supported by our findings we suggest that simultaneous elevation of CA 19-9 and LDH may be predictive for ovarian MCTs [11-13,15,36]. However, since MCTs can contain many different tissue types, we think that studies with larger sample size are needed to understand the specific responses of which tumor markers are elevated when different tissue types are included. In addition to the anatomical region of the teratoma and the age of the patient, it is important to recognize tissues in MCT and rule out the immaturity in teratomas. Therefore, pathologists have a very important role in histopathological evaluation and reliable prognostic profile.

In our study, these features could not be evaluated since we could not reach some data such as admission symptoms and laboratory examination results in all cases. Its retrospective nature is the limitation of our study in this respect.

\section{Conclusion}

Mature cystic teratomas are unilaterally located masses with low tendency for malignant transformation, which are frequently encountered in reproductive women. While, USG is the first-line imaging modality, more detailed information about the mass can be obtained through MRI or CT. Although, very successful results are obtained with laparoscopic surgery, laparotomy is safer in selected cases. 


\section{Compliance with Ethical Standards}

\section{Ethical Committee Approval}

The study was approved by the Pamukkale University, School of Medicine Clinical Research Ethics Committee (approval date and number 19.11.2019-20).

Financial Support: The authors have no relevant financial information to disclose.

Conflicts of interest: The authors declare no conflict of interest.

\section{REFERENCES}

[1] Tewari K, Cappuccini F, Disaia PJ, Berman ML, Manetta A, Kohler MF. Malignant germ cell tumors of the ovary. Obstet Gynecol 2000;95:128-33. doi:10.1016/s0029-7844(99)00470-6

[2] Zalel Y, Piura B, Elchalal U, Czernobilsky B, Antebi S, Dgani R. Diagnosis and management of malignant germ cell ovarian tumors in young females. Int J Gynaecol Obstet 1996;55:110. doi: HYPERLINK "https://doi.org/10.1016/00207292(96)02719-1” It “_blank” 10.1016/0020-7292(96)02719-1

[3] Mohanty MK, Sahu P, Jaiswal AA, et al. A huge immature cervical teratoma, antenatal diagnosis, and its management - an unusual entity. J Clin Neonatol 2013;2:42-5. doi:10.4103/22494847.109249

[4] Peterson CM, Buckley C, Holley S, Menias CO. Teratomas: a multimodality review. Curr Probl Diagn Radiol 2012;41:210-19. doi: HYPERLINK "https://doi.org/10.1067/j. cpradiol.2012.02.001" 10.1067/j.cpradiol.2012.02.001

[5] Maharjan S. Mature cystic teratoma of ovary with squamous cell carcinoma arising from it. Clin Case Rep 2019;7:668-71. doi: $10.1002 / \mathrm{ccr} 3.2062$

[6] Comerci JT Jr, Licciardi F, Bergh PA, Gregori C, Breen JL. Mature cystic teratoma: a clinicopathologic evaluation of 517 cases and review of the literature. Obstet Gynecol 1994;84:22-8.

[7] Wang WC, Lai YC. Evidence of metachronous development of ovarian teratomas: a case report of bilateral mature cystic teratomas of the ovaries and systematic literature review. J Ovarian Res 2017;10:17. doi:10.1186/s13048.017.0313-8

[8] Al-Salem A. Teratoma. In: An Illustrated Guide to Pediatric Surgery. Cham:Springer International Publishing, 2014;63:491-503. doi: 10.1007/978-3-319-06665-3_63.

[9] Rha SE, Byun JY, Jung SE, et al. Atypical CT and MRI manifestations of mature ovarian cystic teratomas. AJR 2004;183:743-50. doi: 10.2214/ajr.183.3.1830743

[10] Hoo WL, Yazbek J, Holland T, Mavrelos D, Tong EN, Jurkovic D. Expectant management of ultrasonically diagnosed ovarian dermoid cysts: is it possible to predict outcome?. Ultrasound Obstet Gynecol 2010;36:235-40. doi:10.1002/uog.7610

[11] Ustunyurt E, Gungor T, Iskender C, Ustunyurt BO, Bilge U, Mollamahmutoglu L. Tumor markers in mature cystic teratomas of the ovary. Arch Gynecol Obstet 2009;279:145-7. doi: 10.1007/s00404.008.0688-2.

[12] Ito K. Significance of CA19-9 in mature cystic teratoma. Nihon Sanka Fujinka Gakkai Zasshi 1992;44:524-28.
[13] Mikuni M, Makinoda S, Tanaka T, Okuda T, Domon H, Fujimoto S. Evaluation of tumor marker in ovarian dermoid cyst. Nihon Sanka Fujinka Gakkai Zasshi 1990;42:479-84.

[14] Var T, Tonguc EA, Ugur M, Altinbas S, Tokmak A. Tumor markers panel and tumor size of ovarian dermoid tumors in reproductive age. Bratisl Lek Listy 2012;113:95-8. doi: HYPERLINK “https://doi.org/10.4149/bll_2012_022" It “" blank" 10.4149/bll_2012_022

[15] Konishi I, Fujii S, Okamura H, et al. Analysis of serum CA125, CEA, AFP, LDH levels and LDH isoenzymes in patients with ovarian tumors-correlation between tumor markers and histological types of ovarian tumors. Nihon Sanka Fujinka Gakkai Zasshi 1986;38:827-36.

[16] Ayhan A, Bukulmez O, Genc C, Karamursel BS, Ayhan A. Mature cystic teratomas of the ovary: case series from one institution over 34 years. Eur J Obstet Gynecol Reprod Biol 2000;88:153-7. doi: HYPERLINK "https://doi.org/10.1016/s0301-2115(99)00141-4" It “_blank” 10.1016/s0301-2115(99)00141-4

[17] Sushma TA, Shashikala K, Sharmila PS, et al. Study of histomorphological changes of teratomas in tertiary care hospital. J Evol Med Dent Sci 2013;2:1771-8.

[18] Kikkawa F, Nawa A, Tamakoshi K, et al. Diagnosis of squamous cell carcinoma arising from mature cystic teratoma of the ovary. Cancer 1998;82:2249-55. doi: HYPERLINK "https://doi. org/10.1002/(sici)1097-0142(19980601)82:11\%3C2249::aidcncr21\%3E3.0.co;2-t" It “_blank" 10.1002/(sici)10970142(19980601)82:11<2249::aid-cncr21>3.0.co;2-t

[19] Outwater EK, Siegelman ES, Hunt JL. Ovarian teratomas: tumor types and imaging characteristics. Radiographics 2001;21:475-90. doi: HYPERLINK "https://doi.org/10.1148/ radiographics.21.2.g01mr09475” It “_blank” 10.1148/ radiographics.21.2.g01 $\mathrm{mr} 09475$

[20] Eskicioglu F, Gokmen T. Evaluation of mature ovarian cystic teratomas in our clinic: 110 cases. Tepecik Egit Arast Hast Dergisi 2016;26:23-6. doi:10.5222/terh.2016.023

[21] Koonings PP, Campbell K, Mishell DR, Jr, Grimes DA. Relative frequency of primary ovarian neoplasms: a 10 year review. Obstet Gynecol 1989;74:921-6.

[22] Partlow WF, Taybi H. Teratomas in infants and children. Am J Roentgenol Radium Ther Nucl Med 1971;112:155-66. doi: HYPERLINK “https://doi.org/10.2214/ajr.112.1.155" It " blank" 10.2214/ajr.112.1.155

[23] Schmoll HJ. Extragonadal germ cell tumors. Ann Oncol 2002;13:265-72. doi: 10.1093/annonc/mdf669

[24] Stany MP, Hamilton CA. Benign disorders of the ovary. Obstet Gynecol Clin North Am 2008;35:271-84. http://dx.doi. org/10.1016/j.ogc.2008.03.004

[25] Caspi B, Appelman Z, Rabinerson D, Zalel Y, Tulandi T, Shoham Z. The growth pattern of ovarian dermoid cysts: a prospective study in premenopausal and postmenopausal women. Fertil Steril 1997;68:501-5. doi: HYPERLINK "https://doi.org/10.1016/s0015-0282(97)00228-8" It “_blank" 10.1016/s0015-0282(97)00228-8

[26] Breen JL, Maxson WS. Ovarian tumors in children and adolescents. Clin Obstet Gynecol 1977;20:607-23. doi: 
HYPERLINK "https://doi.org/10.1097/00003.081.19770900000010” It “_blank” 10.1097/00003.081.197709000-00010

[27] Caruso PA, Marsh MR, Minkowitz S, et al. An intense clinicopathologic study of 305 teratomas of the ovary. Cancer 1971;27:343-48.doi:HYPERLINK"https://doi.org/10.1002/10970142(197102)27:2\%3C343::aid-cncr282.027.0215\%3E3.0.co;2-b" It “_blank" 10.1002/1097-0142(197102)27:2<343::aidcncr282.027.0215>3.0.co;2-b

[28] Varma AV, Malpani G, Agrawal P, Malukani K, Dosi S. Clinicopathological spectrum of teratomas: An 8-year retrospective study from a tertiary care institute. Indian J Cancer 2017;54:576-9. doi: 10.4103/ijc.IJC_294_17

[29] Shin HJ, Kim KA, Kim B-H, et al. Benign enhancing components of mature ovarian teratoma: magnetic resonance imaging features and pathologic correlation. Clin Imaging 2016;40:115661. https://doi.org/10.1016/j.clinimag.2016.08.005

[30] Md Arshad NZ, Ng BK, Md Paiman NA, Abdullah Mahdy $\mathrm{Z}$, Mohd Noor R. Intra-operative frozen sections for ovarian tumors - A tertiary center experience. Asian Pac J Cancer Prev 2018;19:213-18. doi:10.22034/APJCP.2018.19.1.213
[31] Chiang AJ, La V, Peng J, Yu KJ, Teng NN. Squamous cell carcinoma arising from mature cystic teratoma of the ovary. Int J Gynecol Cancer 2011;21:466-74.doi: 10.1097/ IGC.0b013e31820d3e5b

[32] Pradhan P, Thapa M. Dermoid cyst and its bizarre presentation. JNMA J Nepal Med Assoc 2014;52:837-44.

[33] Sahraoui W, Hajji S, Essefi A, et al. Ovary teratoma. Report of 91 cases. Tunis Med 2006;84:349-52.

[34] Drolet J, Dubuc-Lisoir J. Guidelines for the laparoscopic management of the adnexal mass. SOGC 1998;76:1-7. HYPERLINK "https://doi.org/10.1016/S0849-5831(98)800591" doi: 10.1016/S0849-5831(98)80059-1

[35] Uysal F, Balsak D, Uysal A, Incebiyik A, Muratli A, Yildirim Y. Clinical, diagnostic and anatomical aspects of mature cystic teratomas. Austin J Radiol 2014;1:3.

[36] Atabekoğlu C, Bozaci EA, Tezcan S. Elevated carbohydrate antigen 19-9 in a dermoid cyst. Int J Gynaecol Obstet 2005;91:262-3. doi: HYPERLINK "https://doi.org/10.1016/j. ijgo.2005.07.019” |t “_blank” 10.1016/j.ijgo.2005.07.019 